\title{
Prevalence of Intestinal Parasitic Infection and Its Side Effect in School Aged Children in Our Local Region
}

\author{
Zeynep Gökalp Çevik \\ Ihlamurken-t Family Health Center (No:102), Eskisehir, Turkey \\ Email: zeynepgokalpcevikmd@yahoo.com
}

Received 25 July 2015; accepted 11 August 2015; published 17 August 2015

Copyright (C) 2015 by author and OALib.

This work is licensed under the Creative Commons Attribution International License (CC BY). http://creativecommons.org/licenses/by/4.0/

(c) $\underset{\mathrm{EY}}{\mathrm{B}}$ Open Access

\section{Abstract}

Background: The presence of intestinal protozoal infections and parasites is a common and important health problem in our developed country. Our aim of this study was to determine the prevalence of intestinal parasites and protozoa in primary school children, and relationships between the prevalence and family socio-economic status. Patients and Methods: The study population was randomly selected from two schools (rural and urbans), from April 2013 to September 2014. A total of 132 learners ( 85 boys and 47 girls) participated in this research. One of the selected school was a college (S1) and the other one was local goverment school (S2). The children weight, $z$ scores, blood hemoglobin level and family properties such as fathers' employment, etc. have been researched. Parasitological data were collected by analyzing stool samples using Formalin ethyl acetate concentration technique by the department of Biochemistry laboratory in The Goverment Hospital. Symptoms, socio-economic and epidemiologic data were collected by means of a pretested structured questionnaire. Results: Out of 132 learners analyzed, 44.6\% stool samples were positive for ova and cysts of which $34.4 \%$ were known pathogenic parasites. The most common parasite was Giardia intestinalis followed by Dientamoeba fragilis, and Enterobius vermicularis. Occurrence of Blastocystis hominis, H. nana, Taenia spp, and Fasciola spp is low. Our findings showed that there was a significant difference in parasitic infections between S1 and S2 school. Significant associations between parasitic infections and children's family educations were observed. The mean hemoglobin concentration was $96 \mathrm{~g} / \mathrm{L}(7 \pm 1.1)$ and the prevalence of parasitic infections was more than 40 in rural area school children (in S1 school). In total, $41.6 .2 \%$ of children were hungry when they arrived at school from S1. Over $5 \%$ of mothers and $12 \%$ of fathers were illiterate. Conclusion: Our study results demonstrated that parasitic infections in school children were found to be a common and a severe public health problem. Diarrhea, abdominal pain and weight loss were the main symptoms. Lower socio-economic condition and poor sanitation were the main risk factors. In our opinion, the department of Public Heart Centers should explain the reasons to family for preventing intestinal parasitic disease, and explain hygienic conditions importance, and application of supportive programs for the parents. 


\title{
Keywords
}

\section{School Aged Children, Intestinal Parasites, Prevalence, Rural Area, Hygien}

\author{
Subject Areas: Infectious Diseases, Public Health
}

\section{Introduction}

Estimated one billion people in Africa, Asia and the Americas are infected with one or more types of helminth. Although school aged childen's mortality due to intestinal parasitic infections is low, they have detrimental effects on nutrition, growth and cognitive development, contribute substantially to childhood anemia, increase the burden of poverty, impair mental and educational development in children and damage economic productivity. Intestinal parasits are the most common infections especially in rural area in Turkey. Diarrhoea with vomiting due to intestinal inflammation with or without abdominal pain, malnutrition, weight loss and requirement of chronic medical conditions were the most common symptoms in previous publications. In the World, it is estimated that some 3 billion people are affected, and that about 450 million are ill as a result of these infections [1]. Parasitic infections may cause iron deficiency, growth retardation in childhood period. Also, mental health problem is another serious disorder [2]-[5]. The high prevalence of these infections is closely correlated with poverty, poor environmental hygiene and impoverished health services [6]-[8]. The fecal oral route is significant in the transmission of parasitic infections to children because of poor personal hygiene and environmental conditions such as water [9]. Worm infection is believed to be imposing an unnecessary burden on many Turkey children and on the overall cost of health-care [10]. Disadvantaged children are the most affected, especially those who live in densely populated and under-serviced urban informal settlements as well as in some rural areas [10]. World Health Organisation (WHO) members stated that developed countries were urged to implement regular, non-selective de-worming of school-age children 2010 in areas where the prevalence of worm infestation is $50 \%$ or more [11]. Currently, there is scarcity of available literature regarding the prevalence of parasitic infections from the Province; therefore, little is known about intestinal parasitic infections in the inhabitants of the Middle of Anatolian Center. The study was carried out to fill that gap. Thus our aim of this study was to research the prevalence of intestinal parasites in urban and rural primary school children of Eskisehir, Turkey and relationships between socio-economic status.

\section{Patients and Methods}

Eskisehir is located in middle of Turkey and has become an important industrial province during the last decades depending on its rapidly increased population of 800,000, according to the census carried out at the end of 2014 . The two primary schools, are both full-time schools located in the same district of this city. About half of the students live in rural areas. The average number of the students in the classrooms was $25-40$. The number of staff for school satitation in the school was insufficient. Our research showed the number and hygienic conditions of toilets were not conforming to the number and conditions of the criteria published by the Turkish Standard Institute, which required two toilet cabinets for 20 girls and 60 boys.

Frequently, the cream soap and toilet paper were not available in many of schools. To compare between the families educations we filled the special designen form.The annual fee of higher education family was almost 4000 USD per student in the collegue. The average number of students in the classrooms was 20 . The sanitary and the hygienic conditions in this school were conforming. The children food suppliedby the company for the lunch.Therefore the students and the teachers had lunch in this college school under good sanitary and hygienic conditions. The number and the conditions of the toilets in the school were conforming to the criteria specified by the standards. The soap and toilet papers were always available in the toilets in this school.

The number of students examined was higher in college than goverment school. A questionnaire was applied and totally 132 children, 80 were from college, were involved for this research. Of these, stool samples were obtained from all children. The study was approved by Scientific Researches Ethics Committee.

In order to inform the students and their families about the content of the study, a leaflet was given to all children and the procedure for stool sample collection was explained. Sanitary and hygienic conditions and 
water supply of the schools were also reviewed.

\section{Data Collection}

The questionnaire consisting of 18 questions was applied to the students using a face to face by primary care phycian. The socio-demographic information, the social status of families, and the hygienic habits of the student and the health complaints during the last six months were asked.

The questionaires of the forms included sanitary behaviors of the family members, soap use, traditional personal care, drinking water properties (demijohn or rural funtain water), traditional hand-cleaning using antiseptics or soap, frequency of bath for each family member, lavatory properties (include whether soap and/or shampoo), etc.

\subsection{Collection and Examination of Stool Samples}

A universal specimen jar with no preservative, labeled with a unique identification number and the name of the students was distributed to each participating learner. All mothers of participants were asked to collect an early morning stool sample from their child. The samples were then transported in cooler bags to the Goverment Hospital within $2 \mathrm{~h}$ of collection. Stool samples were processed using Formalin ethyl-acetate concentration technique. After concentration a drop of sediment was placed onto a microscope slide and covered with a cover-slip. The entire cover-slip was examined with a $\times 10$ objective for large parasites and $\times 40$ objective for smaller parasites. Results were recorded on a corresponding learner survey form and quantified as +; ++ or +++ according to the parasite load.Specimen examination was performed by a microbiologist. Quality control was carried out by split sampling and parallel staining of known positive samples of fecal parasites.

\subsection{Statistical Analysis}

Statistical significance between the prevalence of intestinal parasites and socioeconomic status determined using the Chi square test and P value less than 0.05 with the help of SPSS 15.0 software, Illinois, Chicago, USA).

\section{Results}

A total of 132 children, aged between 7 - 12 years, (mean $=7.96 \pm 1.29$ ) were examined for intestinal parasites. The parasites detected in the stool samples obtained from the students of both schools are given in Table 1 .

Table 1. Distribution of the intestinal parasites in the students of two primary schools.

\begin{tabular}{|c|c|c|c|}
\hline$\underline{\text { Parasites }}$ & $\underline{\mathrm{S} 1(\mathrm{n}=80)}$ & $\underline{\mathrm{S} 2(\mathrm{n}=52)}$ & $\underline{\text { Total }}(\mathrm{n}=132)$ \\
\hline Pathogenic spp. & $\underline{\mathrm{N}}$ & $\underline{\mathrm{N}}$ & $\underline{\mathrm{N}}$ \\
\hline Giardia intestinalis $^{*}$ & 18 & 3 & 21 \\
\hline Dientamoeba fragilis ${ }^{*}$ & 9 & 3 & 12 \\
\hline Enterobius vermicularis ${ }^{*}$ & 7 & 2 & 9 \\
\hline Hymenolepis nana & 0 & 0 & 0 \\
\hline \multicolumn{4}{|l|}{ Suspicious pathogenic spp. } \\
\hline Blastocystis hominis* & 5 & 1 & 6 \\
\hline Entamoeba histolytica & 4 & 3 & 7 \\
\hline \multicolumn{4}{|l|}{ Non-pathogenic spp. } \\
\hline Entamoeba coli & 1 & 0 & 1 \\
\hline Endolimax nana & 1 & 0 & 1 \\
\hline Iodamoeba bütschlii & 0 & 0 & 0 \\
\hline$\underline{\text { TOTAL }}^{*}$ & $\underline{45(56)}$ & $\underline{12(23)}$ & $\underline{59(44.6)}$ \\
\hline
\end{tabular}

${ }^{*} \mathrm{p}<0.05$. 
The numbers of children with and without parasites in two schools are shown in Table 2. Comparison of two primary schools based on statistically significant characteristics and Family Charecteristics and sanitation properties (Table 3). Of the complaints of the children with parasitic or protozoal infections during last six months, only abdominal pain and anal pruritus were detected. Of the 132 students with abdominal pain, 37.2\% were positive for intestinal parasites, while parasites were detected in many of studentswithout abdominal pain in both groups. $40 \%$ children with anal pruritus in S1, and 6\% of children in S2 children without anal pruritus were found to be positive for intestinal parasites. The relation between intestinal parasites and other complaints such as diarrhoea, nausea, vomiting and lack of appetite were not significantin both groups.

The mean haemoglobin concentration was $96 \mathrm{~g} / \mathrm{L}(7 \pm 1.1)$ and the prevalence of parasitic infections was more than 40 in rural area school children, and the prevalence of parasitic infections was high. In total, $50.2 \%$ of

Table 2. Comparison of two primary schools based on statistically significant characteristics.

\begin{tabular}{|c|c|c|c|}
\hline Characteristics & $\underline{\text { S1 (80) }}$ & $\underline{\mathrm{S} 2(52)}$ & \\
\hline Socio-demographic characteristics & n (\%) & n (\%) & p value \\
\hline Shanty area & 29 & $0(0)$ & \\
\hline City & $21(20)$ & $52(100)$ & $<0.001$ \\
\hline \multicolumn{4}{|l|}{ Education of mother } \\
\hline Uneducated/primary school Incomplete & $23(46)$ & $0(0)$ & $<0.001$ \\
\hline Primary school & $29(49.4)$ & $5(10)$ & $<0.001$ \\
\hline High school and more & $28(35)$ & $48(90)$ & $<0.001$ \\
\hline \multicolumn{4}{|l|}{ Each student has his/her own bedroom } \\
\hline Yes & $13(26)$ & $53(100)$ & $<0.001$ \\
\hline No & $67(74)$ & $0(0)$ & $<0.001$ \\
\hline
\end{tabular}

Table 3. The family characteristics and sanitation properties.

\begin{tabular}{|c|c|c|c|}
\hline \multicolumn{4}{|c|}{ Number of person living in house $(\mathrm{N}=132)$} \\
\hline$\underline{\mathrm{S} 1(\mathrm{~N}=80)}$ & $\underline{\mathrm{S} 2(\mathrm{~N}=52)}$ & $\underline{\mathbf{P}}$ & \\
\hline$\leq 3(\mathrm{~N}=80)$ & 66 & 12 & $<0.001$ \\
\hline$=3(\mathrm{~N}=52)$ & 46 & 6 & \\
\hline \multicolumn{4}{|c|}{ Number of brother/sister $(\mathrm{N}=132)$} \\
\hline$\leq 3$ & $22(27.5)$ & $44(84.6)$ & $<0.001$ \\
\hline$>4$ & 58 & 8 & \\
\hline \multicolumn{4}{|c|}{ Drinking water $(\mathrm{N}=132)$} \\
\hline Treated & 6 & 46 & $<0.001$ \\
\hline Untreated & 66 & 6 & \\
\hline \multicolumn{4}{|c|}{ Washbasin in toilet $(\mathrm{N}=132)$} \\
\hline Yes & $28(35)$ & $52(100)$ & $<0.001$ \\
\hline \multicolumn{4}{|l|}{ Hygienic habits } \\
\hline \multicolumn{4}{|c|}{ Washing hands $(\mathrm{N}=132)$} \\
\hline Only water & $57(71.2)$ & $19(36.5)$ & $<0.001$ \\
\hline With soap and water & $23(29.8)$ & $33(63.5)$ & \\
\hline
\end{tabular}


children were hungry when they arrived at school and $13.4 \%$ worked after school. Over $70 \%$ of mothers and $18.1 \%$ of fathers were illiterate, $16.1 \%$ of fathers were unemployed in S1. The mean number of children in each family was $(5.4 \pm 2.5$, and the mean number of children from each family who attended school was $2.1 \pm 1.1$.

\section{Discussion}

Intestinal parasits are the most common infections throughout the World especially in rural areas in around the world. It is estimated that more then 3 billion people are affected, and that about 450 million are ill as a result of these infections [1]. Parasitic infections may cause anemia due to iron deficiency, growth retardation in children and mental health problems [2]-[5]. The high prevalence of these infections is closely correlated with poverty, poor environmental hygiene and impoverished health services [6]-[8].

Our reseach demonstrated that more than $50 \%$ of the learnerswho is from rural school were positive for intestinal parasitic infections. Students who learned the College the prevalance of the disease was lowest. The demographic data indicated that there were significant differences between the incidence of parasitic infection and the residing area. This may be due to the fact that there were two schools, one was mainly attended by children from a village and the other one by children from aninformal settlement. We observed significant difference when we compared the symptoms such as abdominal distention and pain between two schools. The study also revealed a very high rate of parasitic infections and protozoal colonisation in children who had unemployment parents. We observed that there was a close relationships between poor sanitary and tests for parasitic infection in school aged children. Urban males had a higher prevalence than females, whereas in rural participants females were more infected than males [1] [2]. There was no significant relation detected between the parasitic infections and the age of the learners in both urban and rural areas.

Giardia intestinalis and Dientamoeba fragilis were the common cause of intestinal parasits. However, in recent publications the authors showed the most common helmints as Lumbricoides and Trichirus trichiura [10]. In a study conducted in Lesotho, a neighboring country of South Africa, a high prevalence rate of A. lumbricoides was reported among patients [12]. Samie et collegues reported higher rates of infection by Ascaris in a city of South Africa.

We found the pathogenic protozoan, G. intestinalis to be more prevalent in ourpopulation. We could not distinguish $H$. nana was encountered in urban schools, which is similar to what Adams et al. [11]. But we did find this helmint in our both groups. E. coli was alsoverified asthe most common parasites in a previous study but our findingsdid not correlate Kwitshanas’ study [3]. Thus, these differences showed that the kind of parasitis could be changed from country to country.

Geohelminth infections with Trichuris were zero in our schools, which is contrary to the findings of Ekpo et al., [6] where prevalence of $T$. trichiura was higher among school children in both rural and urban government schools except for private schools. This parasite is normally found in the urine of infected persons and observed in urine analysis. Charcot-Leyden crystals were seen in a few stool specimens. These crystals may also occur in sputum and in tissues [8] [9]. Our results recommendations will assist government public health department, interventions such as deworming and health education programs. Public health awareness campaigns will also be recommended as a high rate of re-infection was observed.

The nutrition, sanitary conditions of the families were insufficient in shantyhouses member was limited due to the high number of children [3]-[5]. The frequency of intestinal parasites was found to be significantly higher in the families living in the shanty areas of the cities than the families living in the other sections of the cities [5]. Intestinal parasites are known to be related to hygiene behaviour closely, the members of the family can easily be infected from each other. The parasites that are transmitted through faecal-oral route may be an important indicator of socio-educational level. Pathogens intestinal parasites were detected in $44.6 .0 \%$ of the school aged children, between 7 - 12 ages. Among pathogen parasites, the incidence of Giardia intestinalis was found at the highest level (15.9\%). The incidences of the non-pathogenic Dientamoeba fragilis and Enterobius vermicularis were also found to be significantly higher.

Our important findis was the low incidence of helminthic infections such as Enterobius vermicularis in both schools. The low incidence of E. vermicularis may be explained by the lack of application of cellophane tape method and the low incidence of other helminths might be related to recovery of hygienic conditions. The similar results were obtained in the studies carried out in another city of Turkey. In contrary, the incidences of A. lumbricoides and T. trichiura was reported between $4.1 \%-41.4 \%$ and $4.9 \%-5.2 \%$, respectively, in two studies 
carried out in Southeast Turkey [10]-[12]. Among the students in S1, 56\% were found to be positive for intestinal parasites and $67 \%$ were living in village area. This data suggested that the incidence of intestinal parasites was not only related to the areas where they live, but also with the socio-demographic features and other factors such as cleaning and health habits of the families. No significant relation was detected between the parasitic infections and the sex of the students. However, a significant relation was found between older students and increased parasite frequencies as in the similar studies. In previous studies from Turkey a number of authors have been researched the intestinal parasitic infections in local areas [13]-[16].

The students who drink the tap water were found to have higher level of parasites than the students who drink commercial drinking water in a sterilised box (12\% and 83\%, respectively); and this result has supported the suggestion that the tap wateruse should be decide to decrease for parasitic infections. In recent study from Argentine, the authors determined that intestinal parasite frequencies detected in various socio-cultural areas were related to contaminated water resources by the parasites, as well as the insufficient health conditions.

\section{Limitation of the Study}

One limitation of this study was that the sample size was not very large and we could cover only two schools. A larger sample from more schools is necessary before generalizing the results to the whole population. Another limitation of the study was that we did not perform the direct stool examination or collect swabs from children with perianal itching, which may have resulted in some underreporting of parasites.

\section{Conclusion}

Abdominal pain, diarrhea, vomiting were the symptoms because of intestinal parasits. Giardia intestinalis and Entamoeba histolytica were the main ones of pediatric group diarrhea. Children's education center is a risk for high prevalence of parasitic infection in rural area. Intestinal parasitic infections in school children were found to be a problem of public health that is on the rise due to lower socio-economic conditions. The factors which significantly increase the incidence of intestinal parasites were uneducated mother, low social status of father, living in crowded houses with insufficient indoor spaces, using the tap water as drinking water, and living at village. People education seminars in school and family houses to prevent the infectious diseases, improving general hygienic conditions and application of supportive programs for the parents may be suggested not only to reduce intestinal parasitic infections, but also to elevate the socio-cultural levels. Intestinal infection and its treatment are the important public problems in developed countries including Turkey. All family members should be examined, undergoing test for detecting the kind of helmints and protozoa, and they should be treated to provide intestinal parasits and protozoa. Use of treated water in damijohn can be lowered intestinal parasitic infections. Access to sanitation and lavatory properties is seemed to be a main factor to decrease of these public infections. Handwashing before eating and after defecating was the other important factor to provide intestinal infection and the symptoms.

\section{References}

[1] Okyay, P., Ertug, S., Gultekin, B., Onen, O. and Beser, E. (2004) Intestinal Parasites Prevalence and Related Factors in School Children, a Western City Sample-Turkey. BMC Public Health, 4, 64. http://dx.doi.org/10.1186/1471-2458-4-64

[2] Ostan, I., Kilimcioğlu, A.A., Girginkardeşler, N., Ozyurt, B.C., Limoncu, M.E. and Ok, U.Z. (2007) Health Inequities: Lower Socio-Economic Conditions and Higher Incidences of Intestinal Parasites. BMC Public Health, 7, 342. http://dx.doi.org/10.1186/1471-2458-7-342

[3] Kwitshana, Z.L., Tsoka, J.M. and Mabaso, M.L. (2008) Intestinal Parasitic Infections in Adult Patients in Kwa ZuluNatal. South African Medical Journal, 98, 709-711.

[4] Alaofè, H., Zee, J., Dossa, R. and O’Brien, H.T. (2008) Intestinal Parasitic İnfections in Adolescent Girls from Two Boarding Schools in Southern Benin. Transactions of the Royal Society of Tropical Medicine \& Hygiene, 102, 653-661. http://dx.doi.org/10.1016/j.trstmh.2008.02.013

[5] Elliott, A.M., Kizza, M., Quigley, M.A., Ndibazza, J., Nampijja, M., Muhangi, L., et al. (2007) The Impact of Helminths on the Response to Immunization and on the Incidence of Infection and Disease in Childhood in Uganda: Design of a Randomized, Double-Blind, Placebo-Controlled, Factorial Trial of Deworming İnterventions Delivered in Pregnancy and Early Childhood. Clinical Trials, 4, 42-57. http://dx.doi.org/10.1177/1740774506075248 
[6] Ekpo, U.F., Odoemene, S.N., Mafiana, C.F. and Sam-Wobo, S.O. (2008) Helminthiasis and Hygiene Conditions of Schools in Ikenne, Ogun State, Nigeria. PLoS Neglected Tropical Diseases, 2, e146. http://dx.doi.org/10.1371/journal.pntd.0000146

[7] Uga, S., Rai, S.K., Kimura, K., Ganesh, R., Kimura, D., Wakasugi, M., et al. (2004) Parasites Detected from Diarrheal Stool Samples Collected in Nepal. Southeast Asian Journal of Tropical Medicine and Public Health, 35, 19-23.

[8] Mehraj, V., Hatcher, J., Akhtar, S., Rafique, G. and Beg, M.A. (2008) Prevalence and Factors Associated with Intestinal Parasitic Infection among Children in an Urban Slum of Karachi. PLoS One, 3, e3680. http://dx.doi.org/10.1371/journal.pone.0003680

[9] Nyarango, R.M., Aloo, P.A., Kabiru, E.W. and Nyanchongi, B.O. (2008) The Risk of Pathogenic Intestinal Parasite Infections in Kisii Municipality, Kenya. BMC Public Health, 8, 237. http://dx.doi.org/10.1186/1471-2458-8-237

[10] Fincham, J. and Dhansay, A. (2012) Worms in SA’s Children. MRC Policy Brief, In Press (Jul 28 ), P 2.

[11] Adams, V.J., Markus, M.B., Adams, J.F., Jordaan, E., Curtis, B., Dhansay, M.A., et al. (2005) Paradoxical Helminthiasis and Giardiasis in Cape Town, South Africa: Epidemiology and Control. African Health Sciences, 5, 276280.

[12] Al-Saeed, A.T. and Issa, S.H. (2006) Frequency of Giardia Lamblia among Children in Dohuk, Northern Iraq. Eastern Mediterranean Health Journal, 12, 555-561.

[13] Alver, O. and Töre, O. (2006) The Prevalance of Intestinal Parasits in Patients who Admitted to Uludağ University Medical Faculty. Turkish Parasitology Journal, 30, 296-301.

[14] Çulha, G., Sangün, Ö. and İncecik, F. (2005) The Prevalance of Intestinal Parasitic Infections in Children Whoes Aged 0-14 in Mustafa Kemal UniversityMedical Faculty. Turkish Parasitology Journal, 29, 255-257.

[15] Değirmenci, A., Sevil, N., Güneş, K., Yolasığmaz, A. And Turgay, N. (2007) The Rate of Intestinal Parasitis in Ege University Medical Faculty Hospital during 2005. Turkish Parasitology Journal, 31, 133-135.

[16] Demirel, M.M., İnceboz, T. and Tosun (Yegane), S. (2003) The Research of Parasitic Infections in The Manisa Moris Sinasi Pediatric Hospital. Turkish Parasitology Journal, 27, 262-265. 